\title{
The "Linked Prosperity" Model as an Integrated Response to Corporate Management Challenges in a Network Society
}

\author{
Vladimir Milovidov \\ Head of Chair, vmilovidov@hotmail.com \\ MGIMO University, 76, Vernadsky ave., Moscow, 119454, Russian Federation
}

\begin{abstract}
$\mathrm{I}$ $\mathrm{n}$ the context of technological and social changes, business faces the challenges of a more complex operating environment. New business models are required that take into account an unprecedentedly wide range of emerging factors. Among such approaches, an integral model stands out, which allows one to adapt to a new level of development of society and master a new context. The approaches to the development of an integral model are still in the process of formation, since a deeper study of the modern network society, its values, guidelines, and preferences is required. Taking into account such complexity requires non-linear approaches and thinking in terms of complex, dynamic systems. From this point of view, when interacting with the increasingly complex environment, it is advisable for companies to view themselves as an element of a large-scale

system of horizontal, social ties, in which the idea of social responsibility acquires new meanings.

It is especially difficult to implement integral approaches within the framework of traditional thinking due to the variety and multi-layered factors that change the context of companies' activities. The transformation of corporate governance and approaches to social responsibility is a nonlinear process driven by a chain of events related to changes in consumer behavior and other aspects. Such exponential changes are characterized by profound and cumulative consequences, radically changing the spheres of activity, social relations, and institutions. This article demonstrates the case of a company that, despite the difficulties, managed to implement a similar approach and maintain a dynamic pace of development.
\end{abstract}

eywords: integrated management model; corporate governance; business model; sustainability; network society; stakeholders; corporate citizenship; linked prosperity; joint-stock companies; corporate social responsibility

Citation: ilovidov V. (2020) The "Linked Prosperity" Model as an Integrated Response to Corporate Management Challenges in a Network Society. Foresight and STI Governance, vol. 14, no 4, pp. 112-120. DOI: $10.17323 / 2500-2597.2020 .4 .112 .120$ 


\section{The Integrated Business Model and the COVID-19 Pandemic}

The social relations system is one of the most complicated study objects whose complexity and the number of dimensions increase as it develops. The modern, ever more complex society is frequently defined as a network society, where direct "peer-topeer" connections begin to dominate the traditional vertical relations system. The transformation process is far from complete and develops nonlinearly. Global network companies and decentralized autonomous organizations (DAOs), based on distributed ledger technology (DLT) and operating exclusively in a virtual environment, are emerging and rapidly growing. In an increasingly complex context, the ability to anticipate future managerial, social, and technological innovations becomes critical. In recent decades, the following areas have emerged in the literature: the development of new corporate governance theory; transformation factors of traditional business models; and business performance assessment criteria in changing conditions. Today these areas converge in corporate social responsibility (CSR) and sustainable business model studies. Actually, the whole range of approaches to managing business processes and building relationships with external and internal actors is being consolidated.

Initially, ensuring companies' transparency and accountability was on the agenda. Between 1988 and 2008 the corpus of English-language publications in the US and UK containing the term "corporate governance" or the abbreviation "CSR" increased at least ten-fold. By now not only quantitative indicators of public and scientific interest in the topic have changed, but also qualitative ones.

Other new concepts have emerged in addition to CSR, such as stakeholders and "corporate citizenship", along with the "corporate governance 2.0" concept [van der Elst, Vermeulen 2011; Visser, 2011; Subramanian, 2015] which takes into account all technological advances and radical shifts in public mentality, including those reflected in the "sustainable development" model. In another area, an attempt was made to rethink and suggest a new business model which would take into account changing consumer preferences, increased global competition, aggravated climate and environmental issues, a shift in social values, and the emergence of a new generation interested in radically different consumer properties of products and services [Drucker, 1994; Porter 1996; Johnson et al. 2008; Upward, Jones, 2015]. As the number of publications increased, it became more closely related to sustainability [Boons, Ludeke-Freund, 2013; Geissdoerfer et al. 2018], which is a key marker of the transformation taking place in the public mind and corporate governance [Page, Spira, 2016].

The Web of Science and Scopus databases currently comprise over 4,000 publications whose titles include the term "business model", and about 470 articles with the term "sustainable business model" [Geissdoerfer et al. 2018]. The convergence of business model and corporate governance studies allows one to assess the relationship and complementarities between these concepts. The development of long-term strategies, business planning, modeling, and improvement of corporate governance essentially addresses common issues, which among other things suggests that the social structure is becoming more complicated, with its numerous levels increasingly connected with one another. According to a basic principle of the UK Corporate Governance Code updated in 2018, a successful company aims to achieve long-term sustainable success, increase its capitalization, and create social benefits [FRC, 2018]. Thus, the goal of top company management merges in three aspects: social responsibility, sustainability, and profitability. At the current stage, this traditional objective acquires a new dimension, so it is being accomplished in the scope of the complex dynamic systems concept. This means social benefits must be taken into account when making decisions at different levels. The criteria for achieving this goal are so diverse, they are difficult to formalize. Qualitative, volatile psychological aspects of assessing entrepreneurial activity and strategies' effectiveness are becoming no less important than financial and economic performance indicators. Problems also arise with setting priorities for a wide range of stakeholders.

Accordingly, it would make sense to address not corporate governance and business models separately, but an integrated management model (IMM). Along with the traditional objectives of achieving financial stability, reducing costs, and increasing value, it is aimed at building relationships between the company and society, and promoting social development.

Despite the significant number of publications on the subject, practical examples of IMM application are few, though some experience in this area has been accumulated, while attempts to design such a model were made long before the need for it was realized. One of the case studies, the company Ben \& Jerry's, will be presented below.

Let us consider the components of such an integrated model suitable for meeting current and future challenges, including the changing social attitude towards business activities, companies' social responsibility, and company management's attempts to make the IMM the basis of long-term development strategies and corporate governance systems' transformation. These cases have the potential to become the mainstream of a new governance concept in the medium term. The consistent transformation of corporate governance and approaches to responsibility is a nonlinear process triggered by a series of changes in consumer behavior and company management, which can be described in complex system terms. The 
starting points of nonlinear changes can be called exponentially scalable events (ESE), which bring about profound and cumulative consequences and, at a certain time, will radically change a particular area of activities, the established social relations, or institutions [Milovidov, 2015a,b, 2017, 2019]. ESEs include the ongoing transformations in the theory and practice of corporate governance, often caused by unexpected and unpredictable external factors, especially those that emerged in 2020.

The World Economic Forum (WEF) report "The Universal Purpose of a Company in the Fourth Industrial Revolution" published at the end of 2019 summarizes the evolution of corporate social responsibility over more than the past two decades [Schwab, 2019]. However, just three months after its release, the outbreak and the rapid spread of the COVID-19 coronavirus pandemic highlighted the need to adjust this and other documents describing corporate responsibility standards. COVID-19 is an example of an ESE which has affected all areas of public life, especially consumer choice and behavior. The interdependence of participants in global supply chains becomes quite evident. Many companies are faced with the need to cut jobs or even terminate their operations; remote employment has proliferated while biological safety problems have become very much relevant. Accordingly, business models and corporate responsibility criteria have changed too. Already in April 2020 the WEF suggested the "Stakeholder Principles in the COVID Era" which clarify and adjust the approaches to responsible business conduct [WEF, 2020].

The Organisation for Economic Cooperation and Development (OECD) came up with a similar initiative in response to the rising COVID-19 coronavirus crisis [OECD, 2020], focusing on supporting and strengthening relationships between key economic agents: employees, suppliers, consumers, authorities, shareholders, and other actors. The need to preserve the existing business ecosystems, strengthen security, and take into account the interests of all stakeholders, even at the cost of short-term economic benefits, was recognized. In turbulent crisis conditions, such measures make it possible to balance the expectations of business and society, thus confirming the viability of the previously adopted integrated management models, including the one under consideration here. The coronavirus crisis has shown that the traditional corporate governance model based on a relatively narrow understanding of productivity, which did not take into account the interests of various parties, was no longer viable. Moreover, its shortcomings hinder the transition to a new business model. Companies cannot build up benefits for themselves without providing them for society as a whole. It would also be impossible to maintain one's positions after a sudden disruption of economic and social ties due to unexpected crises.

An IMM is designed to balance corporate and public interests, that is, high profit margins and an acceptable level of the company's social responsibility.

Ignoring the need to integrate the business model and corporate governance is fraught with serious risks and, as a result, with long-term and nonlinear negative consequences for the company and society as a whole.

\section{The Transformation of Public Mentality}

The integrated business model concept emerged due to the natural evolution of the relationship between business and society. In recent decades, a clear trend towards management innovation became apparent. The advances of big data technologies and content analysis allow one to consider the public's changing interests, its openness to certain ideas, scientific trends, and everyday narratives which define the public mentality.

Google Trends (GT) and Google Ngram Viewer $(\mathrm{GNV})^{1}$ are among the most effective and accessible tools for studying the dynamics of collective mentality. The first allows one to track changes in the content of the most frequent search queries since 2004, while the second makes it possible to assess the frequency of terms' and concepts' use in book publications (the coverage period ranges from 1800 to 2008).

At present the database of publications processed by the GNV algorithm exceeds 8.1 million titles ( $8 \%$ of all books published in the world), with a total volume of over 860 billion tokens [Michel et al., 2011]. Figure 1 shows the number of mentions of such concepts as "social", "international", "state", and "community" per 1 million words in Englishlanguage books in the Google collection published in the respective year. For example, in 2008, the term "state" was used 379 times per million words, "social" 336 times, "community" 172, and "international" 112 times. They are closely associated with the main development trends including changing attitudes toward the state, attention to social issues, internationalization of economic activities, and the increased role and activity of local communities including civic associations, self-government bodies, and so on.

Another cross-section of social change is shown in Figure 2: it compares the frequency of using the words "network", "industrial", "digital", and "global". These terms are also strongly associated with the current internationalization processes and the rapid development of digital technologies. 
Figure 1. Frequency of Mentions of the Words Social, International, State, and Community per 1 Million Words in English-Language Publications in 1800-2008

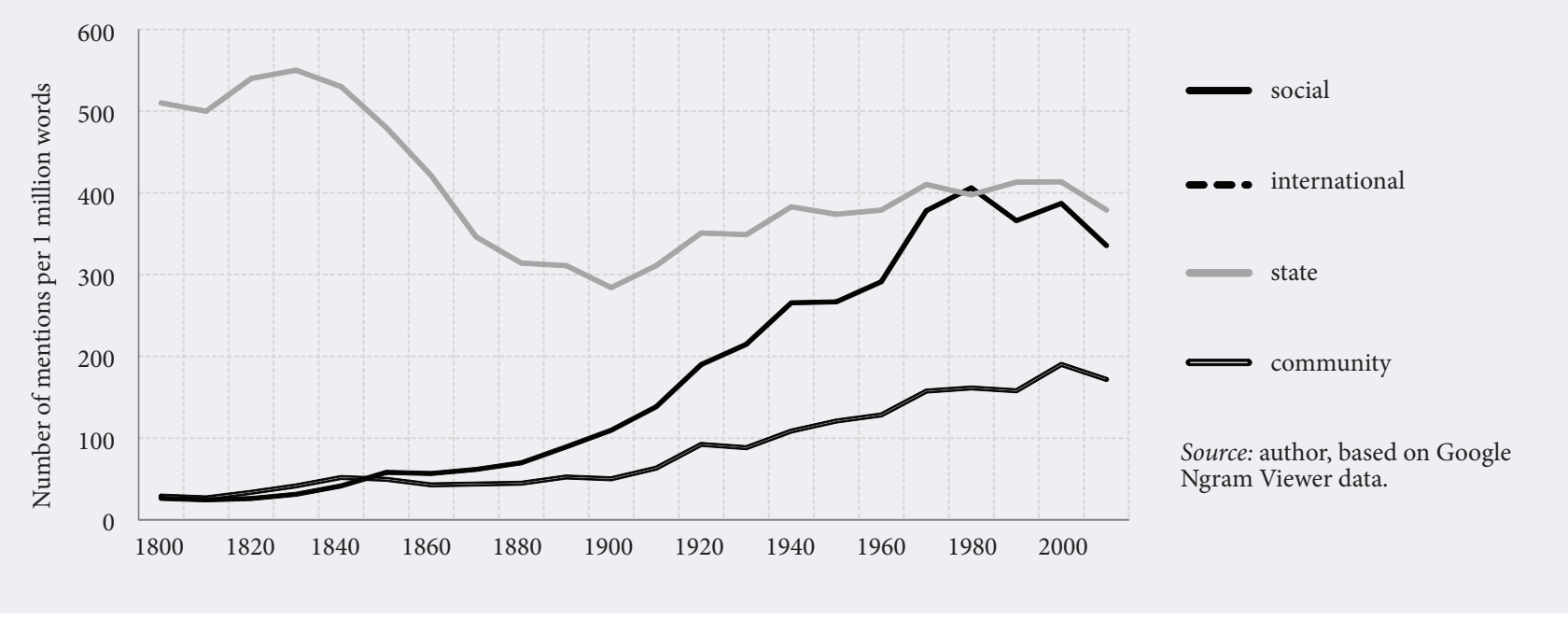

The presented data becomes especially useful when the two graphs are combined. Figure 3 illustrates the transformation of societal attitudes over more than two centuries. For example, the word "state" was most frequently mentioned in 1830 , "industrial" in 1970, "social" in 1980, "network", "international", and "community" in 2000, and "global" in 2008. The changes in the frequency of mentioning the terms in question allow one to assess the changes in the essential characteristics of societies of the $19^{\text {th }}$-early $21^{\text {st }}$ centuries.

The first type, which dominated until the 1970s, can be called the state-industrial society, and the one that replaced it at the turn of the $21^{\text {st }}$ century is the global network society. These characteristics are notional and do not match the common periodization of the industrial and post-industrial structures. However, this typology seems to be valid and is confirmed by many contemporary facts which are not reflected in the "post-industrial" concept.

At the state-industrial stage, individual countries interacted with each other. Physical boundaries, spheres of influence, and international competition were of fundamental importance. The modern global network context is based on "peer-to-peer" connections on the global scale and various forms of social self-organization including social networks. Physical boundaries remain but become permeable in the virtual environment of the internet, international communications, and trans-boundary knowledge and idea exchanges. In the new context, rigidly hierarchical connections do not make up the entire system of values of the participants in the global socio-humanitarian environment.
The new type of society gives rise to appropriate attitudes, behavioral rules, and values that transform the traditional approaches to business management. Radical changes are expected in this area, the signs of which are already apparent in the activities of companies more perceptive to disruptive innovations. However, the first serious attempts to adapt management practices to the changing business environment can be traced back to the 1980s. One such model is "linked prosperity", which implies sharing benefits between companies, stakeholders, customers, and the general public. In other words, the linked prosperity model merges three aspects: companies' profits, their sustainability, and social responsibility.

The food industry company Ben \& Jerry's was one of the first to apply the new approach, having made it its mission to "create linked prosperity for everyone". ${ }^{2}$ A holistic vision allowed it to anticipate the radical changes in business process management. Ben \& Jerry's new strategy can be seen as a unique IMM which made it possible to detect the deep systemic shifts in social values that were radically changing the nature of fundamental classical economics concepts such as utility, profit, costs, property, and so on.

The company merged the elements of two business models: a classic one, aimed at increasing profitability indicators, and a new model that takes into account the interests of many parties including shareholders, suppliers, contractors, customers, local communities, and others, with an emphasis upon CSR. Ben \& Jerry's simultaneously pursues three goals: production (making high-quality, constantly 


\section{Table 1. Innovative Elements of the Linked Prosperity Model}

\begin{tabular}{|l|l|l|l|}
\hline \multicolumn{1}{|c|}{ Innovations } & \multicolumn{1}{c|}{ Production process } & \multicolumn{1}{c|}{ Business sustainability and productivity } & \multicolumn{1}{c|}{ Social responsibility } \\
\hline Product & Invention, R\&D & Competitiveness, market leadership & Socially determined use value \\
\hline Management & $\begin{array}{l}\text { Cooperation, division of } \\
\text { labor }\end{array}$ & $\begin{array}{l}\text { Productivity, maximizing revenues and profits, } \\
\text { CSR }\end{array}$ & $\begin{array}{l}\text { Optimizing total social benefits } \\
\text { (TSB) }\end{array}$ \\
\hline Marketing & $\begin{array}{l}\text { Context, perception, } \\
\text { experience }\end{array}$ & Increasing sales & $\begin{array}{l}\text { Emergence of intangible social } \\
\text { values }\end{array}$ \\
\hline Source: author. & \multicolumn{2}{|l}{} \\
\hline
\end{tabular}

improved products), economic (increasing sales), and social (supporting employment, implementing local social programs, etc.) [Michalak, 2019]. This broad formula benefits all participants in the value chain: company employees, suppliers, customers, local communities, and so on. The company came up with this approach back in 1988, when the ideas of CSR, corporate citizenship, and stake holding were in their infancy, and even the very concept of a business model had not yet become the focus of academic research. Though product, management, and marketing innovations have emerged in response to global challenges, Ben \& Jerry's has been able to quickly conquer a large segment of consumers who share social justice, equality, and responsibility ideas (Table 1). By introducing the linked prosperity model, Ben \& Jerry's made the product significantly more complex, enriching it with new social content and turning it into a kind of cultural phenomenon. In this case the product concept went beyond meeting a simple nutritional need. The consumer value became a socially determined use value.

The management model under consideration also incorporates the fair-trade principle: minimizing the economic inequality of integral production participants. Cooperation ties are supplemented by supporting small and medium-sized businesses, introducing limits on the difference in compensation for junior and senior employee positions (no more than five times), and social programs to support local communities in the regions where the company and its partners operate. Social benefits and CSR were combined with consumer value. Increasing profits gave way to a new goal: maximizing total social benefits.

In line with the traditional business modeling principles, Ben \& Jerry's was increasing sales to recoup the costs and accomplish its social mission. At the same time the intangible values of its corporate culture promoted demand for its products. In "experience economy" terms [Pine, Gilmore, 1998], to promote its products on the market, the company offered both new products and unique consumer experience.

Let us take a closer look at specific elements of the linked prosperity model as reference points for implementing an IMM in the emerging network society, namely creating TSB, maximizing it, and generating and monetizing intangible social values. Both social goal-setting and consumer value are important. Product innovations are expected to complement objective consumer properties of products with value dimension, which increases demand for them. The end result of such innovations is the production of TSB, while products turn into

\section{Figure 2. Frequency of Mentions of the Words Network, Industrial, Digital, and Global per 1 Million Words in English-Language Publications in 1800-2008}
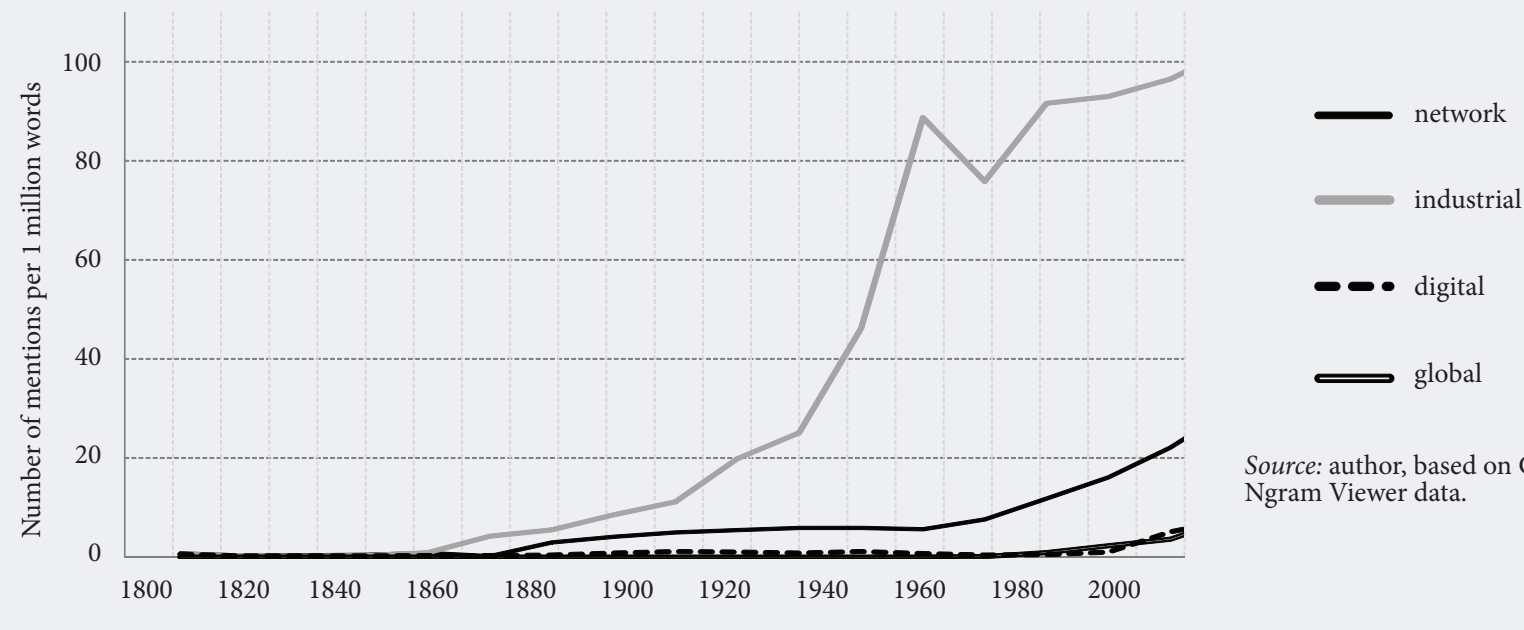

Source: author, based on Google Ngram Viewer data. 
Figure 3. Frequency of Mentions of the Words Social, State, International

(main scale from 0 to 600 words), and Network, Industrial, Global, and Community (auxiliary scale from 0 to 120 words) per 1 Million words in English-Language Publications in 1800-2008

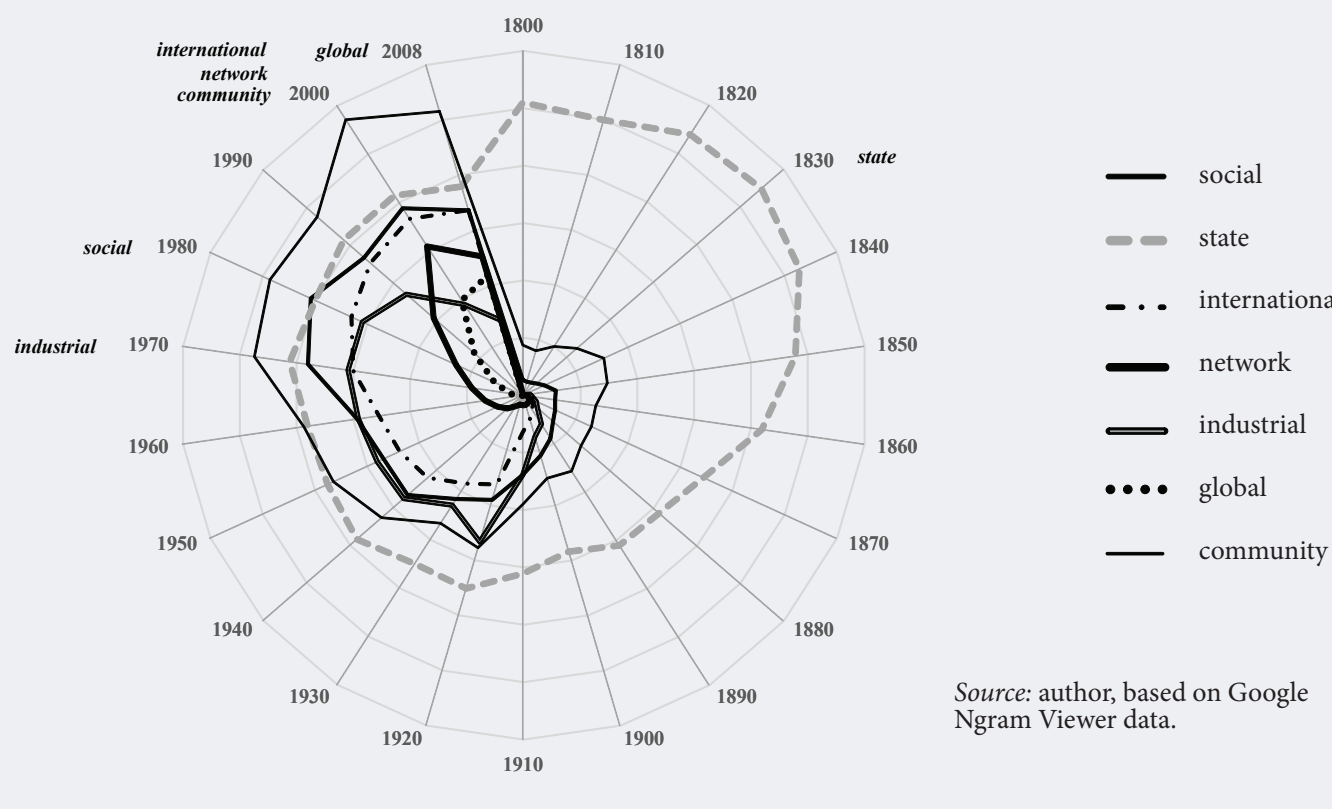

a social self-identification mechanism (joining the group), which is demonstrated by the example of the younger generation. Intangible factors such as quality of life, state of environment, interpersonal relations, and overall social context of products and services are becoming increasingly important for younger people. Members of new generations starting with millennials (born in 1981 and onwards) are convinced that producers must make qualitative changes to society [Deloitte, 2018, 2019; Goleman, 2019]. Attempts to take into account the changes in their values have obvious economic implications: annual expenditures of this social group are estimated at about $\$ 600$ billion and expected to reach $\$ 1.4$ trillion by 2020 [Gallup, 2016].

\section{Maximizing Social Benefits and Optimizing Profits}

The shift in emphasis in assessing products' consumer properties, the incorporation of social content into their physical characteristics also affect entrepreneurial goals, which is reflected in the frequency of mentions of the terms "profit", "revenue" and "benefits". Figure 4 shows the gradual decrease in the frequency of mentions of the word "revenue". The popularity of the term "profit" in English-language literature grew until the 1920s and began to steadily decline after 1940 . At the same time, there was an exponential growth in the frequency of mentions of the word "benefit", which today is actually at its historic maximum. The presented data also reflects the changes in the consumer attitudes of younger generations, which prompt companies to create managerial innovations, including increasing the total social benefits of their activities.

Finding a balance of interests that can promote the growth of companies' profits and total social benefits at the same time remains an important task. The example of Ben \& Jerry's shows that betting on the linked prosperity model at a certain stage may negatively affect economic indicators for a certain amount of time, but then it will be possible to achieve equilibrium followed by growth.

\section{Intangible Values and Tangible Assets}

Incorporating social content into consumer value requires businesses to implement a broad set of measures which go beyond marketing innovations and take into account the nonlinear patterns of complex systems.

Whereas previously it was enough for companies to accomplish the objective of maximizing profits, now the context has become more complicated: they must also take into account a variety of social signals. The CSR factor as a corporate governance system element should be taken into account in strategic business planning, assessed, and balanced against the expected additional profits. Unlike the usual intangible resources, CSR emerges during companies' interaction with society. The result is a positive or negative assessment of the company's social responsibility, and thus of its products' matching public interests. In the first case this can promote demand for products, and the willingness to pay a premium reflecting the higher socially determined use value 


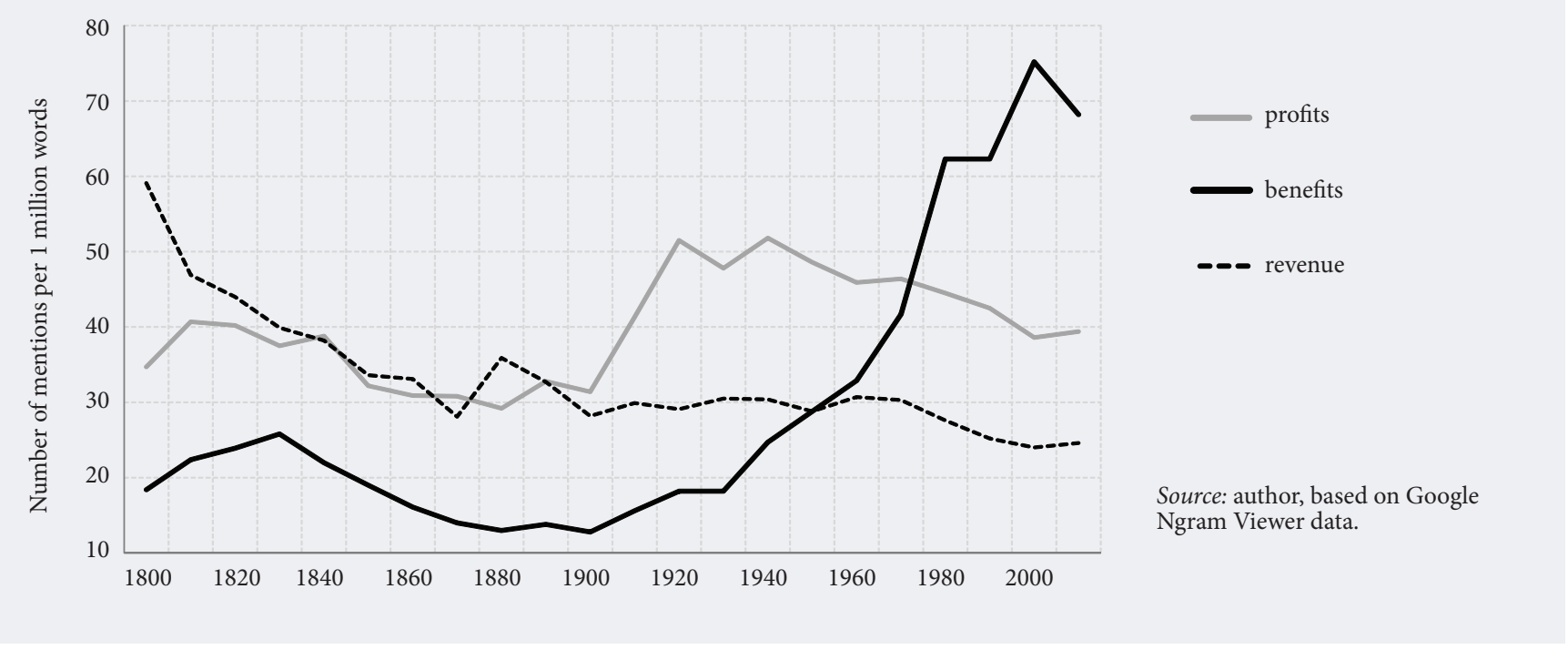

[Laroche et al., 2001]. In the second case, the interest in products will decline, followed by a decline in profits. The company will have to cut costs and output or apply compensatory measures that would increase the consumer value of the product. The network society factor enhances all effects (positive or negative alike), since information about and user reviews of the company and its products are instantly disseminated across the global network. CSR affects pricing: young consumers are willing to pay more for products of companies which adhere to appropriate standards (in Ben \& Jerry's case, its ice cream). On the financial market, despite trend volatility, companies that follow CSR standards tend to have a higher potential for profitability.

Sustainable investments vary widely by country or by CSR program profile. In 2018 they amounted to $\$ 30.7$ trillion in total, the bulk of which was made in Europe (46\%) and the US (39\%), and smaller shares in Japan (7\%), Canada (6\%), and Australia and New Zealand (2\%) [GSIA, 2019]. The highest growth of social investments was noted in Japan: a record $6,700 \%$ in 2014-2017. Companies' socially responsible behavior has a positive effect on decisionmaking, both by buyers and investors, while CSR becomes an intangible asset that generates added value [Hellsten, Mallin, 2006].

\section{Conclusions}

The development of digital technologies leads to the transformation of both economic actors and social values. New, more complex development patterns emerge, which include the integrated corporate governance model. It takes into account a wider range of various factors and trends: the emergence of socially determined demand and the corresponding consumer value; increased demand for greater total social benefit from entrepreneurial activities; and a greater role for social values in the production of goods and services. These aspects are important in forecasting profits, creating corporate value, and interacting with partners, customers, and the external environment.

In the near future, the integrated approach to management will reach a new level due to the continuous development of digital technologies, and thus of society. This will lead to a radical revision of business performance criteria. Given the growing importance of business reputation as an intangible social value, the methodology for its quantitative assessment will be improved, along with the approaches to forecasting risks, opportunities, and changing preferences and values of potential target audiences. Active customer groups' priorities are changing by becoming more complex and multi-layered.

The emergence of new business models must be taken into account, such as product and service sharing, minimizing the negative impact upon the environment, and so on. Company executives will have to build up their competencies and knowledge of complex systems and take them into account in strategy development. Meanwhile their responsibilities are expanding and the role of the social component in company reporting is growing.

New corporate standards allow one to adequately assess financial aspects of sustainable development initiatives such as environmental and social programs, or new responsible governance techniques. Entrepreneurial success will largely depend upon how flexible and responsive companies are to social innovations prompted by the development of the network society. 


\section{References}

Boons F., Ludeke-Freund F. (2013) Business model for sustainable innovation: state-of-the-art and steps toward a research agenda. Journal of Cleaner Production, vol. 45, pp. 9-19. DOI: 10.1016/j.jclepro.2012.07.007.

Deloitte (2018) Deloitte Millennial Survey. Millennials Disappointed in Business Unprepeared for Industry 4.0. Available at: https://www2.deloitte.com/content/dam/Deloitte/global/Documents/About-Deloitte/gx-2018-millennial-surveyreport.pdf, accessed 26.06.2020.

Deloitte (2019) The Deloitte Global Millennial Survey 2019. Societal Discord and Technological Transformation Create a "Generation Disrupted". Available at: https://www2.deloitte.com/global/en/pages/about-deloitte/articles/ millennialsurvey, accessed 26.06.2020.

Drucker P.F. (1994) The Theory of the Business. Harvard Business Review, vol. 72 (September-October), pp. 95-104.

FRC (2018) UK Corporate Governance Code, London: Financial Reporting Council. Available at: https://www.frc.org. uk/getattachment/88bd8c45-50ea-4841-95b0-d2f4f48069a2/2018-UK-Corporate-Governance-Code-FINAL.pdf, accessed 06.01.2020.

Gallup (2016) How Millennials Want to Work and Live. Available at: https://www.gallup.com/workplace/238073/ millennials-work-live.aspx, accessed 26.06.2020.

Geissdoerfer M., Vladimirova D., Evans S. (2018) Sustainable business model innovation: A review. Journal of Cleaner Production, vol. 198, pp. 401-416. DOI: 10.1016/j.jclepro.2018.06.240.

Goleman D. (2019) Millennials: The purpose generation. Available at: https://www.kornferry.com/institute/millennialspurpose-generation, accessed 26.06.2020.

GSIA (2019) Global Sustainable Investment Review. Global Sustainable Investment Alliance Report 2019, Brussels, Sydney, London, Utrecht, Washington D.C.: Global Sustainable Investment Alliance Available at: http://www.gsi-alliance.org/ wp-content/uploads/2019/03/GSIR_Review2018.3.28.pdf, accessed 30.10.2019.

Hellsten S., Mallin Ch. (2006) Are "Ethical" or "Socially Responsible" Investments Socially Responsible? Journal of Business Ethics, vol. 66, no 4, pp. 393-406. DOI: 10.1007/s10551-006-0001-x.

Johnson M.W., Christensen C.M., Kagermann H. (2008) Reinventing Your Business Model. Harvard Business Review, vol. 87, December issue, pp. 52-60.

Laroche M., Bergeron J., Barbaro-Forleo G. (2001) Targeting consumers who are willing to pay more for environmentally friendly products. Journal of Consumer Marketing, vol. 18, no 6, pp. 503-520. DOI: 10.1108/EUM0000000006155.

Michalak R. (2019) The key metric is how Ben \& Jerry's measures success. Fast Company, 01.05.2019. Available at: https://www.fastcompany.com/90287777/this-key-metric-is-how-ben-jerrys-measures-success, accessed 26.06.2020.

Michel J.B., Shen Y.K., Aiden A.P., Veres A., Gray M.K. (2011) Quantitative Analysis of Culture using Millions of Digitized Books. Science, vol. 331, no 6014, pp. 176-182. DOI: 10.1126/science.1199644.

Milovidov V.D. (2015a) Upravlenie innovatsionnym protsessom: kak effektivno ispol'zovat' informatsiyu [Management of Innovation: How to Effectively Use the Information]. Neftyanoe Khozyaistvo, no 6, pp. 10-16 (in Russian).

Milovidov V.D. (2015b) Upravlenie riskami v uslovijah asimmetrii informatsii: otlichai otlichimoe" [Risk management under information asymmetry: To differentiate those distinguishable], World Economy and International Relations, no 8, pp. 14-24 (in Russian).

Milovidov V.D. (2017) Informacionnaya asimmetriya i "bol'shie dannye": gryadet li peresmotr paradigmy finansovogo rynka [Information Asemmetry and Big Data: Should Financial Market Paradigm Be Revised]. World Economy and International Relations, vol. 61, no 3, pp. 5-14. DOI: 10.20542/0131-2227-2017-61-3-5-14 (in Russian).

Milovidov V.D. (2019) Symmetry of Delusions: Factors of the Financial Market Uncertainty under the Technological Revolution, Moscow: Magistr (in Russian).

OECD (2020) Tackling Coronavirus (COVID-19). Contributing to a Global Effort. COVID-19 and Responsible Business Conduct, Paris: OECD. Available at: http://www.oecd.org/coronavirus/policy-responses/covid-19-and-responsiblebusiness-conduct-02150b06/, accessed 02.06.2020.

Page M., Spira L.F. (2016) Corporate governance as custodianship of the business model. Journal of Management and Governance, vol. 20, no 2, pp. 213-228. DOI: 10.1007/s10997-016-9343-7.

Pine II B.J., Gilmore J.H. (1998) Welcome to the experience economy. Harvard Business Review (July-August), pp. 97-105. 
Porter M.E. (1996) What is the strategy? Harvard Business Review, vol. 74, November-December issue, pp. 61-78.

Schwab K. (2019) Davos Manifesto 2020: The Universal Purpose of a Company in the Fourth Industrial Revolution, Geneva: World Economic Forum. Available at: https://www.weforum.org/agenda/2019/12/davos-manifesto-2020the-universal-purpose-of-a-company-in-the-fourth-industrial-revolution/ accessed 02.06.2020.

Subramanian G. (2015) Corporate Governance 2.0. Harvard Business Review, vol. 93, no 3, pp. 96-105.

Upward A., Jones P.H. (2015) An ontology for strongly sustainable business models: Defining an enterprise framework compatible with natural and social science. Organization \& Environment, vol. 29, no 1, pp. 97-123. DOI:10.1177/1086026615592933.

van der Elst Ch., Vermeulen E.P.M. (2011) Corporate Governance 2.0: Assessing the Corporate Governance Green Paper of the European Commission. European Company Law, vol. 8, no 4, pp. 165-174. Available at: https://research. tilburguniversity.edu/en/publications/corporate-governance-20-assessing-the-green-paper-of-the-european, accessed 06.01.2020.

Visser W. (2011) CSR 2.0: Transforming the Role of Business in Society. Social Space, no 4, pp. 26-35. Available at: https://ink.library.smu.edu.sg/lien_research/87/, accessed 06.01.2020.

WEF (2020) COVID Action Plan. Stakeholder principles in the COVID era, Geneva: World Economic Forum. Available at: http://www3.weforum.org/docs/WEF_Stakeholder_Principles_COVID_Era.pdf, accessed 02.06.2020. 